\title{
Numerical Exploration of Influence of Phase Changing Material in Heat Transfer Augmentation in the Double Tube Heat Exchanger
}

\author{
C. Gnanavel ${ }^{1 *}$, R. Saravanan ${ }^{2}$, M. Chandrasekaran ${ }^{3}$ \\ ${ }^{I}$ Asst. Professor, Department of Mechanical Engineering, VISTAS, Chennai, India. \\ ${ }^{2}$ Professor, Department of Mechanical Engineering, Ellenki College of Engineering \& Technology, Hyderabad, Telangana, India. \\ ${ }^{3}$ Professor, Department of Mechanical Engineering, VISTAS, Chennai, India. \\ *Corresponding author E-mail:gnanavelmech1986@gmail.com
}

\begin{abstract}
The double tube heat exchanger is a device in which the inner tube carries the hot fluid. Phase Changing Material is the energy storage device is used for Solar heater applications to maintain the constant temperature, in the present study of this work is CFD Analysis of plain tube heat exchanger with Phase Changing Material (PCM) and without Phase Changing Material (PCM), Charging time, liquid volume fraction with the various Heat Transfer Fluid (HTF) inlet temperature 70, 75, 80 deg Celsius and various flow conditions of laminar flow of $2000 \mathrm{Re}$, Transition flow of $4000 \mathrm{Re}$ and Turbulent flow of 10,000 Re
\end{abstract}

Keywords: Double tube heat exchanger, PCM, solidification, melting, numerical study, heat transfer fluid, RT50, mass flow, velocity.

\section{Introduction}

The Thermal Energy Storage System (TESS) is one which employs as a heat stabilizer in the heat transfer applications. In general, the thermal energy can be efficiently stored by means of Latent Heat Thermal Storage System (LHTSS) with use of Phase Changing Materials (PCM). The PCM has storage to volume ratio at approximately constant temperature. PCM changes its phase from solid to liquid when it exposes to heat and transfer it phase liquid to solid while heat transfer vice versa. Recently, some of the investigations were reported. [1] reported by numerical investigation that the $146 \%$ penetration, reduction of melting time of PCM by $14.6 \%$ cab be achieved by including the nano-particles up to $5 \%$ in volume in a shell tube heat exchanger during the melting. [2] Discussed the various possibilities of augmentation of performance of LHTSS and the significance of PCM heat exchanger to achieve the best result among the other four LHTSS.

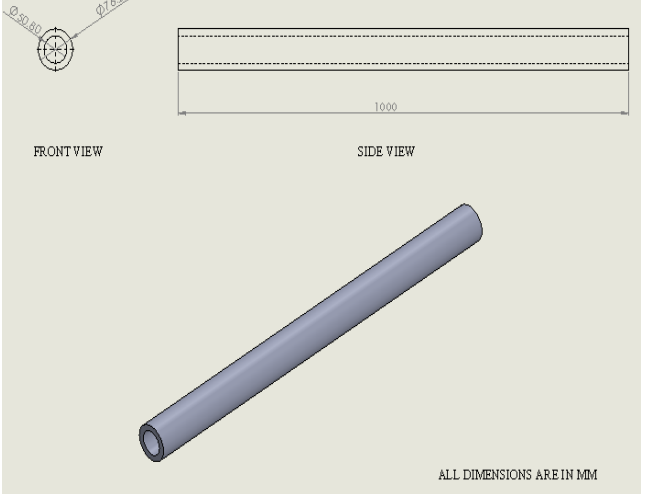

Fig. 1: The inner tube of DPHE with PCM

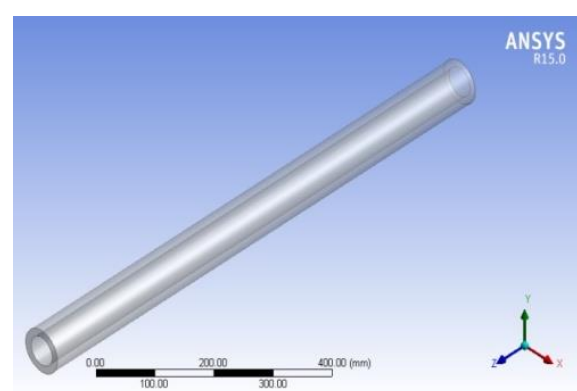

Fig. 2: Model of tube of DPHE with PCM

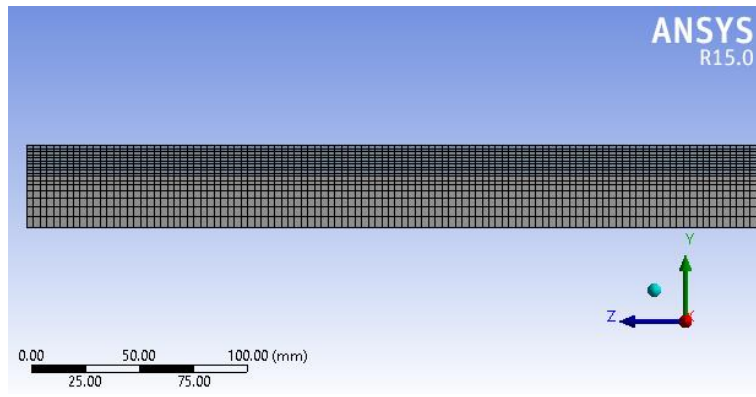

Fig. 3: Mesh diagram of tube of DPHE with PCM

[3] Ensured by numerical study followed by experimentation on melting and solidification in a shell and tube LHTSS that temperature field hasn't reached steady state during the experimentation due to water as heat transfer fluid and its high value of Prandtl number. The Heat transfer has also slowed and low, but the velocity field fully developed in a short period of time. [4] Presented review about LHTESS. [5] reported after studied numerically and experimented that the inlet temperature of heat transfer fluid and the tube radius influence more than mass 
flow rate of heat transfer fluid and thickness of the tube, in the process of melting and solidification of PCM in the a shell and tube type heat exchanger. SS and about PCM. The literature $[2,4]$ motivated this research using PCM in double tube heat exchanger. [6] experimented with wax as PCM and studied about its melting and solidification while HTF flows in side the tube and concluded that both the processes are conquered by natural convection while melting and conduction while solidification. [7] introduced the PCM embedded in a graphite matrix in LHTSS of double pipe [7] experimented and numerically evaluated the melting behavior of PCM of paraffin wax in a cylindrical capsule. The study reports that the factor like capture radius and HTF inlet temperature influencing more. The temperature of phase change of material melting behavior must be considered in range from start and finish of such phase change took place. [8] suggested including nanoparticle for augmenting the PCM performance in a threedimensional cavity [9] examined the melting performance of Phase changing material in different shape of the container of LHTSS like cylindrical, rectangular, shell and tube and reported that storage of thermal energy is almost same irrespective of shape of the container of LHTSS but the cylindrical shape gave faster melting rate out performs and mass of PCM proportionate to the energy stored in the LHTSS. [10, 11] investigated the influence PCM added tube type such as bare tube and finned-tube on melting and solidification of PCM at various mass flow rate, at various inlet temperature of heat transfer fluid and at various fin pitch and reported that finned tube did not sensibly affect the melting and solidification of PCM than bare tube heat exchanger. In this research the tube and shell formed a double tube heat exchanger. The PCM packed in between the minimum radius of the outer tube and maximum radius of inner tube. The PCM RT50 is preferred for the investigation, the objective of this work to study the melting and solidification of PCM based heat exchanger.

\section{Numerical Approach}

\section{Governing Equations}

The tube with PCM model of double pipe heat exchanger is shown in the figure 2. The unit length of 1 meter considered for analysis. The PCM is filled (solid phase) in the gap between the diameters of $50.8 \mathrm{~mm}$ and $76.2 \mathrm{~mm}$ in the tube throughout of its length. The ends of the pipe sealed for the PCM well. The common heat transfer fluid, the water is preferred. The water flows in the inner shell of the tube diameter $50.8 \mathrm{~mm}$. the RT50 grade PCM was preferred and its selected properties furnished in the Table 1 .

Table 1: Properties of Phase Changing Material - RT50

\begin{tabular}{|l|l|}
\hline Description of Properties & Quantity \\
\hline Density & $780 \mathrm{Kg} / \mathrm{m} 3$ \\
\hline Heat capacity at constant pressure $(\mathrm{Cp})$ & $2000 \mathrm{~J} / \mathrm{Kg} \mathrm{K}$ \\
\hline Thermal conductivity $(\mathrm{K})$ & $0.2 \mathrm{~W} / \mathrm{m} \mathrm{K}$ \\
\hline Dynamic viscosity $(\mu)$ & $0.006 \mathrm{Kg} / \mathrm{m} \mathrm{S}$ \\
\hline Latent heat $(\mathrm{L})$ & $168000 \mathrm{~J} / \mathrm{Kg}$ \\
\hline solidification Temperature (Tsolidus) & $318 \mathrm{~K}$ \\
\hline Liquefaction (Tliquidus) & $324 \mathrm{~K}$ \\
\hline
\end{tabular}

The enthalpy porosity method employed for simulating the phase changing material RT50 in which it was set that the porosity in each cell equal to the liquid fraction in that cell [39-40]. The Navier-Stokes equation used for viscous incompressible flow representation, the thermal energy equation used for describing the annulus space and the viscous dissipation term was neglected. It was assumed that the heat transfer fluid velocity is fully developed and the fluid properties are constant and independent of temperature changes. As per notation of [7] the following equations ate furnishes

The Continuity equation assumed that $\nabla \cdot \vec{V}=0$
The Momentum equation for the heat transfer fluid may be written as

$\frac{\partial V}{\partial t}+\vec{V} \cdot \nabla \vec{V}=\frac{1}{\rho}\left(-\nabla P+\mu \nabla^{2} \vec{V}+\rho \vec{g} \beta(T-T\right.$ ref $\left.)\right)+\vec{S}$

The Energy equation for the heat transfer fluid may be termed as

$\frac{\partial h}{\partial t}+\frac{\partial H}{\partial t}+\nabla \cdot(\vec{V})=\nabla \cdot\left(\frac{k}{\mathrm{c} \mathrm{p}} \nabla h\right)$

The total enthalpy of the material is the sum of the latent heat and its sensible enthalpy

$H=h+\Delta H$

Where sensible enthalpy can be obtained from the following equation

$h=h r e f+\int_{T r e f}^{T} C p d T$

and the latent heat of the material is

$\Delta H=\lambda L, 12-12: 306-6: 30$

Where the latent heat $(\Delta H)$ of the PCM varies from zero to $L$. The value zero assigned for solid state and the $L$ for liquid state. Hence the liquid fraction of PCM can be defined with following boundary conditions.

When

$$
\begin{aligned}
& \lambda=(\Delta H / L)=0 \text { if } \quad T<T_{S} \\
& \lambda=(\Delta H / L)=1 \text { if } T>T_{\text {Liquid }} \\
& \lambda=(\Delta H / L)=\left(T-T_{S}\right) /\left(T_{\text {Liquid }}-T_{S}\right) \text { if } T_{S}<T<T_{\text {Liquid }}
\end{aligned}
$$

On convective heat transfer, the momentum equation is to be added for considering the phase effect. Hence the same can be termed in terms of Darcy's law damping term $\overrightarrow{(S)}$

$\vec{S}=\left\{(1-\lambda)^{2} / \lambda^{3}\right\} A_{m u s h} \vec{V}$

At present the mushy zone constant ()

The amplitude of the velocity damping or the coefficient of mushy zone is nowadays considered as 106 . So the same was executed in this study.

\section{Boundary Conditions and Initial Conditions}

The entire system is initially assumed at $300^{\circ} \mathrm{K}$ temperature $\left(T_{0}\right)$. The flow parameter i.e. Reynolds Number $\left(R_{e}\right)$ considered three levels as 2000, 4000 and 10,000. The system is insulated i.e., there is no heat transfer from the system to surrounding vice versa. The water inlet temperature $\left(T_{i n}\right)$ varied in three levels as $70^{\circ}, 75^{\circ}$ and $80^{\circ}$ ). At these temperatures, the flow velocities are observed and investigated.

\section{Numerical Procedure and Validation}

The finite volume method is employed to numerically solve this kind of problem. This is transient 3D problem by SIMPLE (SemiImplicit Pressure-Linked Equation) algorithm may be used to solve the pressure-velocity coupling equations and the pressure correction equation by PRESTO scheme.The QUICK differencing scheme used for momentum and energy equations. After investigated numerical solution for independency, the grid size of 16,000 is found adequate for this study from the available like $9,000,13,000,16,000$ and 19,000 cells. The convergence criterion for energy is $10^{-6}$, for momentum equation is $10^{-5}$ and for the continuity equation is $10^{-5}$. 

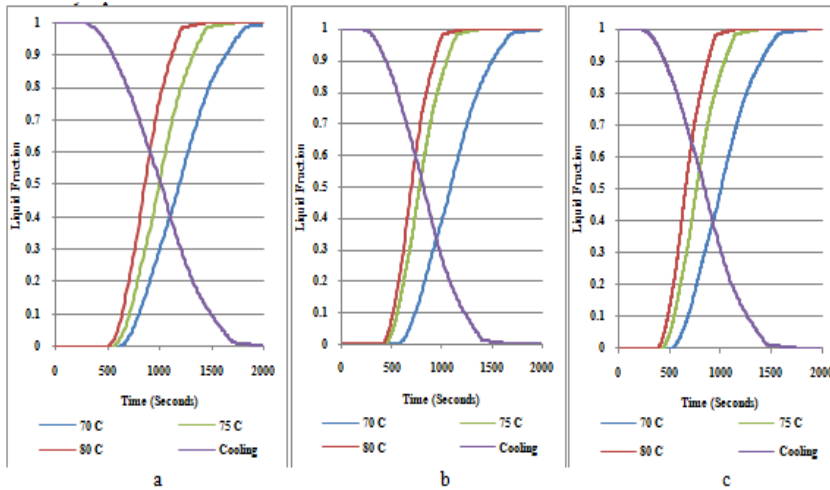

Fig. 4: Liquid fraction with respect to time at inlet temperatures at flow of a) At $R_{e}=2000$ b) at $R_{e}=4000$ c) $R_{e}=10000$

The Figure 4 depicted the liquid fraction trend with respect to time at different inlet temperatures of the water. The heat transfer rate is depends on temperature difference and hence the higher the temperature will cause the higher heat transfer rate. Refer the figure 4 , The heat transfer rate in the descending from $80^{\circ} \mathrm{C}$ to $70^{\circ} \mathrm{C}$. and the cooling curve shoe in opposite direction.

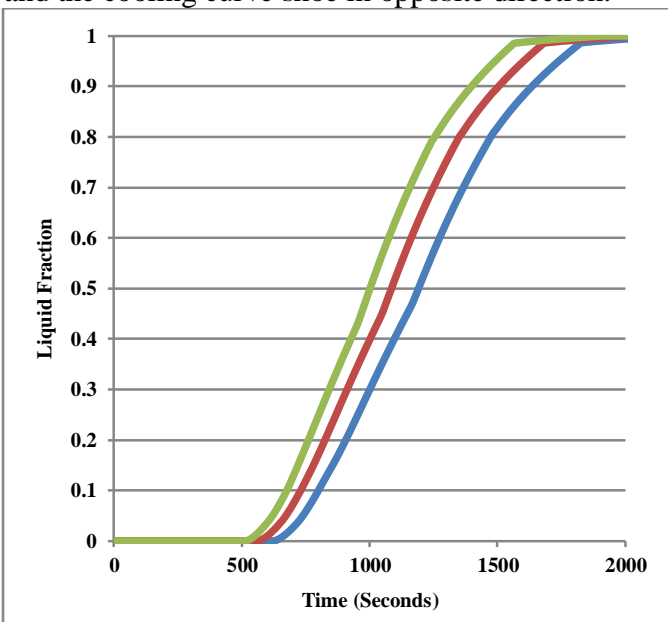

$2000 \mathrm{Re}$
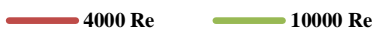

Fig. 5: Liquid fraction Vs flow velocities (heating)

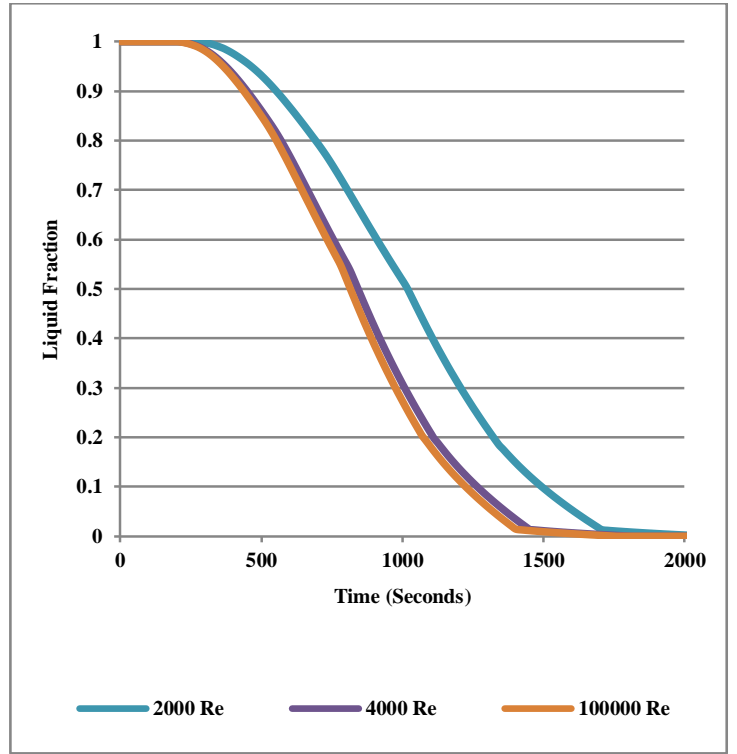

Fig. 6: Liquid fraction Vs Flows velocities (cooling)

The figure 5 illustrates the liquid fraction's variation at various flow velocities with respect to time when the water inlet temperature of $70^{\circ} \mathrm{C}$ at the turbulence the heat transfer is better than laminar and the nter mediate flow. Hence the flow condition with Reynolds number of 10000 highest, heat transfer than others. That is the melting rate of the Phase Changing Material RT50 is found high. The figure 6 explains that liquid fraction with respect to time for different flow conditions (that is Re values) while cooling. The heat transfer either heating or cooling the highest flow velocity that is at turbulence will be higher. So the flow with Re of 10,000 yielded faster cooling rate that the solidification rate of phase changing material RT50. [12][13]
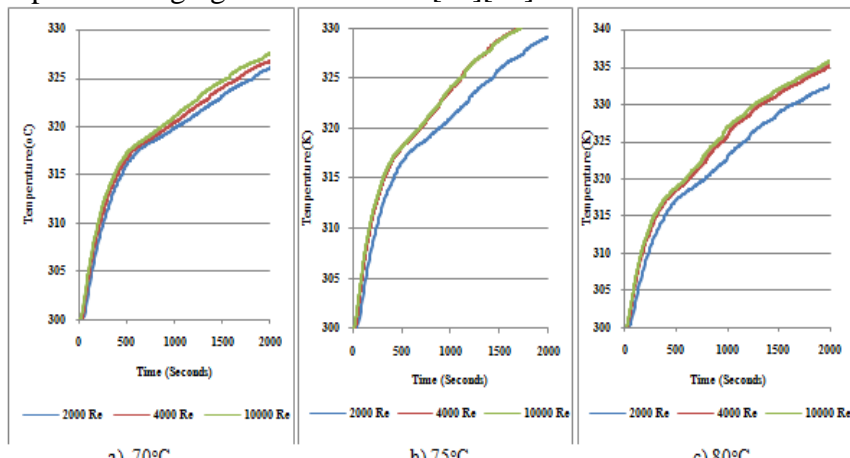

Fig. 7: Temperature hike performance with respect to time for various flow conditions at water inlet temperatures

The Figure 7 depicts the temperature performance with respect to for different flow condition at different water inlet temperatures while heating and for cooling performance is depicted in Figure 8

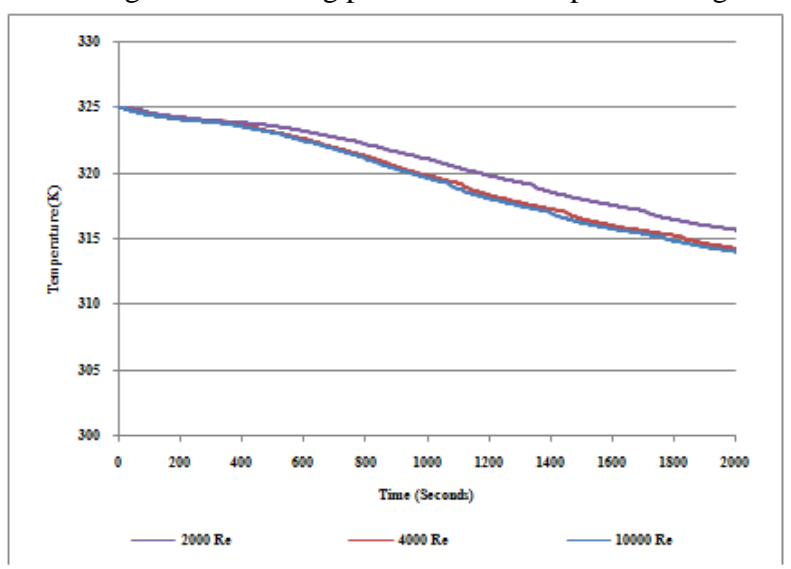

Fig. 8: The fall of temperature with respect to flow velocities while cooling

Figure 8 shows the temperature with respect to flow velocities for cooling of the PCM. The cooling rate is not much affected by the flow velocity of the fluid. The cooling rate slightly increases with the increasing flow velocity.

\section{Conclusion}

The Investigation heating and cooling time of PCM in the double pipe heat exchanger tube with PCM is analyzed. The analysis included the inlet temperature variation $\left(\right.$ as $70^{\circ} \mathrm{C}, 75^{\circ} \mathrm{C}$ and $80^{\circ} \mathrm{C}$ ) of the Heat transfer fluid (water), flow velocity variation (Re values 2000, 4000 and 10,000) were considered at three levels and analyzed. According to the results of this numerical investigation and in general the phase changing material RT50 increases the heat transfer rate better and smooth. The other specific conclusions are:

- The influence of water inlet temperature is most significant than the flow velocity in the melting of PCM RT 50.

- The increase the flow rate of water in the tube increases the melting rate of PCM and area of melting too because of turbulence of flow increases.

- The increase of inlet temperature of the water increases the potential to melt the phase changing material RT50 
temperature and drastically reduced the melting time i.e., $26.5 \%$ time reduction when increase the water inlet temperature from $70^{\circ} \mathrm{C}$ to $75^{\circ} \mathrm{C}$ and melting time reduction by $39.1 \%$ when raising the water inlet temperature from $70^{\circ} \mathrm{C}$ to $80^{\circ} \mathrm{C}$.

- The influence of flow rate found less in the melting rate of PCM RT50, i.e., increases from $R_{e}=2000$ to $R_{e}=4000$ the PCM RT50 melting rate increased from 0.039 to 0.079 . if the flow rate increased from $\mathrm{R}_{\mathrm{e}}=2000$ to $\mathrm{R}_{\mathrm{e}}=10,000$ the PCM RT50 melting rate increased from 0.039 to 0.1977 and the reduction of melting time $15 \%$ and $24.5 \%$ respectively.

\section{References}

[1] Hosseini MJ, Ranjbar AA, Sedighi K \& Rahimi M, "Melting of nanoprticle-enhanced phase change material inside shell and tube heat exchanger", Journal of Engineering, (2013).

[2] Jegadheeswaran S \& Pohekar SD, "Performance enhancement in latent heat thermal storage system: a review", Renew. Sustain. Energy Rev, Vol.13, (2009), pp.2225-2244

[3] Trp A, "An experimental and numerical investigation of heat transfer during technical grade paraffin melting and solidification in a shell-and-tube latent thermal energy storage unit", Sol. Energy, Vol.79, (2005), pp.648-660.

[4] Agyenim F, Hewitt N, Eames P \& Smyth M, "A review of materials, heat transfer and phase change problem formulation for latent heat thermal energy storage systems (LHTESS)", Renew. Sustain. Energy Rev, Vol.14, (2010), pp.615-628

[5] Kibria MA, Anisur MR, Mahfuz MH, Saidur R \& Metselaar IHSC, "Numerical and experimental investigation of heat transfer in a shell and tube thermal energy storage system", Int. Commun. Heat Mass Transf, Vol.53, (2014), pp.71-78.

[6] Surendar, A. (n.d.). Short communication: Role of Microbiology in the Pharmaceutical \&Medical Device. 433| International Journal of Pharmaceutical Research, 10(3).

[7] Medrano M, Yilmaz MO, Nogués M, Martorell I, Roca J \& Cabeza LF, "Experimental evaluation of commercial heat exchangers for use as PCM thermal storage systems", Appl. Energy, Vol.86 , (2009), pp.2047-2055

[8] Ranjbar A A , Kashani S, Hosseinizadeh SF \& Ghanbarpour M, "Numerical heat transfer studies of a latent heat storage system containing nano-enhanced phase change material", Therm. Sci., Vol.15, No.1, (2011), pp.169-181.

[9] Vyshak NR \& Jilani G, "Numerical analysis of latent heat thermal energy storage system", Energy Convers. Manag, Vol.48,(2007) pp.2161-2168

[10] Rahimi M, Ranjbar AA, Ganji DD, Sedighi K, Hosseini MJ, Bahrampoury R, "Analysis of geometrical and operational parameters of PCM in a fin and tube heat exchanger", Int. Commun. Heat Mass Transf, Vol.53, (2014), pp.109-115.

[11] Rahimi M, Ranjbar AA, Ganji DD, Sedighi K \& Hosseini MJ, "Experimental investigation of phase change inside a finned-tube heat exchanger", Journal of Engineering, (2014).

[12] G, Abikhanova, A Ahmetbekova, E Bayat, A Donbaeva, G Burkitbay (2018). International motifs and plots in the Kazakh epics in China (on the materials of the Kazakh epics in China), Opción, Año 33, No. 85. 20-43.

[13] G Cely Galindo (2017) Del Prometeo griego al de la era-biós de la tecnociencia. Reflexiones bioéticas Opción, Año 33, No. 82 (2017):114-133 